\title{
ПРОЕКТНОЕ ФИНАНСИРОВАНИЕ В СИСТЕМЕ УПРАВЛЕНИЯ ПРИВЛЕЧЕНИЕМ ИНВЕСТИЦИЙ В ИНФРАСТРУКТУРНЫЕ ПРОЕКТЫ
}

\author{
(c) 2019 Зельднер Алексей Григорьевич \\ доктор экономических наук, профессор, главный научный сотрудник \\ Институт экономики Российской академии наук, Россия, Москва \\ E-mail: tzeldner@gmail.com
}

В статье рассматривается одна из перспективных форм финансирования концессий - проектное финансирование. Этот метод позволяет финансировать инфраструктурные проекты за счет использования долгосрочных кредитов и их погашения за счет полученной от проекта прибыли.

Ключевые слова: инфраструктура, инвестиции, проектное финансирование, управление, кредит.

В течение продолжительного времени по мере становления рыночных отношений и меняющегося соотношения между государством и рынком в удельном весе собственности, основных фондов, объеме прибыли и инвестиций, все больший вес приобретают институты государственно-частного партнерства, обеспечивающие за счет софинансирования условия для решения общественных инфраструктурных (социальных и производственных) проектов, обеспечивающих воспроизводственный процесс.

Общественная инфраструктура - это основа стабильности социально-экономического развития любого общества. Этому способствует обязанность государства по формированию объектов общественной инфраструктуры как экономической, так и социальной. Решение постоянно возрастающих инфраструктурных проблем осуществляется государством в зависимости от состоянии бюджета, а также путем привлечения частного бизнеса за счет создания соответствующих институтов и механизмов, возможно и заключение прямых контрактов.

В мире инфраструктурные инвестиции считаются самыми эффективными инструментами стимулирования экономического роста и развития. В России по отношению к ВВП совокупные инвестиции в инфраструктуру (государственные и частные) снижаются с 2011 по 2016 г. на 0,2\% в год. В среднем за последние пять лет удельный вес в инфраструктуре инвестиций составил $1,88 \%$ ВВП; в мире в среднем $3,2 \%$ ВВП, в Индии $-4-4,5 \%$, в Китае $-7-8 \%$ ВВП [1]. В этой связи, учитывая значимость инфраструктуры обоснованным следует признать выделение на реализацию инфраструктурных проектов $24,5 \%$ общих расходов (25,7 трлн. руб.) на национальные проекты на ближайшие шесть лет [2].

Многообразие целей, стоящих перед Россией в деле инфраструктурного обустройства предопределяет и использование многообразия форм ГЧП с учетом соблюдения правового поля, интересов сторон, распределения рисков (особенно таких как инвестирование сторон, риск оплаты потребителем полученных услуг и др.). Эксперт Всемирного банка Д. Делмон так суммировал существующие представления о формах ГЧП: «...коммерческие соглашения и контрактные конструкции, которые применимы к ГЧП, чрезвычайно разнообразны по формам. Классификация ГЧП Всемирного банка - это не ограничивающее предписание публичному сектору использовать конкретные схемы из числа названных, а, скорее, примеры того, какими методами частная компания может быть вовлечена в проект. Можно утверждать, что нет идеальной схемы, кроме той, которая лучше всего учитывает условия страны, отрасли, проекта или содержание проблемы» [3].

Следует учитывать, что при проектном финансировании финансируется компания, реализующая проект, она же ведет все расчеты, погашая кредиты за счет доходов, полученных проектом. При инвестиционных и коммерческих кредитах - погашение их за счет общей деятельности.

В общем, следует отметить, что принципиальное различие между проектным финансированием и прочими проектами состоит в том, что проекты привлечение кредитов обеспечивают активами организации, а их возмещение осуществляется за счет общих финансовых результатов, в проектном финансировании возмеще- 
ние только доходами, полученными в процессе реализации проекта.

Из разнообразия форм ГЧП, включая концессии, сервисные контракты, договора аренды и управления, особые экономические зоны, остановимся на концессионных соглашениях и их разновидностях. Выделяют следующие виды концессий: строительство-управлениепередача; восстановление-аренда-передача; модернизация-управление-передача и другие. Все эти виды отличаются схемами финансирования.

Необходимость опережающего развития инфраструктурных проектов, как условие экономического роста, вынуждает искать методы их финансирования, в том числе и без наличия у концессионеров залогового имущества. Это и предопределило достаточно широкий интерес к проектному финансированию. В этом случае все риски относятся на проектную организацию, (которая создается как юридическое лицо).

Использование проектного финансирования в концессионных соглашениях в значительной мере связано с модификацией схемы ВТО (строительство-передача-эксплуатация) и далее проектирование-строительствофинансирование-эксплуатация (управление) (DB). При этом за частным бизнесом остается «право эксплуатировать объект и получать доходы от реализации, а не от владения.

Как показывает мировой и отечественный опыт, рост концессионных проектов - это использование эффективного методов финансирования, к которым относится «проектное финансирование». Это, по сути, метод финансирования инфраструктурных проектов за счет использования долгосрочных кредитов под залог будущей выручки от проекта. Проектное финансирование предполагает тесную увязку крупных инфраструктурных проектов и их кредитование с погашением полученной прибыли от проекта.

Механизм проектного финансирования кроме возврата кредита за счет денежных средств самого проекта, предполагает формирование специальной проектной компании, отработку системы гарантий, охватывающей риски, как заемщиков средств, так и участников проектной компании. Важным представляется распределение рисков таким образом, чтобы они учитывали только те риски, которые непосредственно связаны с теми элементами управления, которыми они располагают.

Важнейшим фактором эффективной реализации инфраструктурных проектов с использованием механизма проектного финансирования выступает договоренность сторон о реальном производстве (добыче) того или иного продукта и соответствующих обязательствах по их приобретению, то есть гарантия связки спроспредложение, это - ключ к проектному финансированию. В России такой проект под названием «Голубой поток» был реализован Россией и Турцией при заключении соглашения о поставке газа в Турцию (30 млрд. куб.м в год)*.

По мнению профессора Йескомба Э.Р., финансирование крупных проектов - это не только форма проектного финансирования, но это «форма финансового инжиниринга - заимствования под залог денежных средств, полученных от проекта. Оно зависит от подробной оценки рисков, связанных со строительством, эксплуатацией, получением доходов и распределением их среди инвесторов, кредиторов и других участников договорных и прочих отношений. По существу, это прекрасно подходит для финансирования проектов ГЧП. Проектное финансирование - не то же самое, что финансирование проектов, потому что проекты финансируются множеством разных способов. Например, за счет государственных заимствований, при помощи системы государственных закупок, не прибегая к ГЧП» [4].

Проектное финансирование - высоко рискованный проект, особенно учитывая, что речь идет о крупных и долговременных проектах. Поэтому могут возникнуть политические, правовые и экономические риски, последние связаны с ценами, тарифами, колебанием курса ва-

\footnotetext{
* Финансирование проекта «Голубой поток» осуществлялось следующим образом: «ОАО Газпром и Blue Stream Pipeline Compani B. V. привлекли 1,1 млрд. долл. под гарантии агентств экспортного кредитования ряда стран во главе с итальянским экспортно-страховым агентством SACE. Причем SACE в соответствии со своей внутренней политикой предоставило гарантии только на 95\% всего кредита. Остальные 5\% составил риск, который банкикредиторы приняли непосредственно на себя. Компания SNAM выступила гарантом по ссудам на общую сумму 866 млн. долл. И в том, и в другом случае финансирование было предоставлено консорциумом, в который входят более 30 банков во главе с банками West LB, Banca Commerciale Italiana и Mediocredito». (http://www.old.rcb. $\mathrm{ru} /$ archive/articles.asp?id=3395)
} 
лют и др. Это приводит к сложностям получения кредитов в отечественных банках, как правило, требуется залог и гарантии, желательно государственные.

Кредитование осуществляется банками под крупные проекты по схеме синдицированного кредита пула банков или же путем заключения отдельного договора банков на какую-то часть проекта. Процентная ставка колеблется в зависимости от наличия гарантий и рискованности проекта. Следует отметить, что при синдицированном кредите происходит и распределение рисков, что весьма существенно для инвесторов. В то же время проектное финансирование отличается существенной дифференциацией проектов (в разрезе отраслей), и каждый проект в своем роде уникален и практически вряд ли повторим*

В России программа инвестиционного обеспечения инфраструктурных проектов на основе проектного финансирования была принята 11 октября 2014 г. и утверждена Правительством РФ Постановлением № 1044, затем постоянно модифицировалась, последняя редакция датируется 30.12 .2018 г.

Важнейший вопрос проектного финансирования - кредитование. В указанном выше постановлении правительства госкорпорации Внешэкономбанк (Банк развития и внешнеэкономической деятельности) поручено выполнять функции агента Правительства РФ по вопросам предоставления и исполнения госгарантий по кредитам, привлекаемым российскими юридическими лицами в целях реализации инвестпроектов на основе проектного финансирования. Во-вторых, размер кредитной ставки не должен превышать уровень процентной ставки, устанавливаемой Центральным банком при предоставлении уполномоченным банкам кредитных средств в целях рефинансирования кредитов, выданных уполномоченными банками конечным заемщикам [5], плюс 2,5\% годовых [6]. Это, по сегодняшней оценке, высокие кредитные ставки, целесообразно пойти на льготные став- ки кредитования, типа тех, что используются в сельском хозяйстве, и также следует установить мораторий на изменение ставки по проекту для долгосрочных проектов как минимум на треть срока. При таком подходе отпадает «право уполномоченного банка на увеличение процентной ставки по кредиту исключительно при условии увеличения ставки рефинансирования Центрального банка» в рамках настоящей программын*.

При отборе инвестиционных проектов на основе проектного финансирования их полная стоимость определяется как сумма всех затрат (без учета процентов по кредитам) и должна составлять не менее 1 млрд. руб. и не более 20 млрд. руб. Причем финансирование за счет заемных средств должно составлять не более 20 млрд. руб.

В 2016 г. постановлением Правительства РФ от 1.11.2016 г. № 1119 введены правила предоставления гарантий РФ по кредитам, выделенным в целях проектного финансирования. Гарантии предоставляет госкорпорациям Внешэкономбанк в объеме до 25\% фактически предоставленной суммы кредита. Решение о предоставлении гарантий оформляется приказом Минфина РФ и предоставляется на сумму не менее 0,2 млрд. руб. и не более 4 млрд. руб. на срок, установленный кредитным договором, увеличенный на 90 календарных дней [7].

В России проектное финансирование в большей мере используется в сфере добычи природных ресурсов; из вариантов можно привести такой известный международный проект, как «Сахалин-2». «В данном проекте более половины акций принадлежит «Газпрому», около 30\% Shell Sakhalin Holdings B.V., 12,5\% акций - Mitsui Sakhalin Holdings B.V. и т.д. Реализация международных проектов позволяет применять имеющийся мировой опыт в области проектного управления, привлекать дополнительные инвестиции в российскую экономику, использовать современные инновационные технологии, оптимизировать систему налогообложения и др.» [8].

\footnotetext{
* Варианты проектного финансирования отрабатывались на проектах, связанных с добычей природных ресурсов в штате Техас в 1930 г., а в Европе в Северном море в 1970-е годы. Проектное финансирование использовалось при прокладке газопроводов, а в сфере общественного назначения его связывают со строительством туннеля под Ла-Маншем.

** В проекте программы о материалах по механизму проектного финансирования, подготовленной Минэкономразвития в июне 2014 г., эффективная процентная ставка для банка-заемщика проектировалась на уровне ключевой ставки Банка России минус 1\% годовых в рублях. Для условий 2018-2019 гг. это достаточно приемлемая кредитная ставка.
} 
Проектное финансирование, при прочих равных условиях, может найти широкие возможности для использования в национальных проектах. Выступая на съезде РСПП, президент В. Путин подчеркнул, что с 1 июля 2019 г. «должна заработать безопасная для граждан схема финансирования жилищного строительства. Деньги будут поступать не сразу застройщику, а на спецсчет в банк и списываться только в обмен на новое жилье. Строительным компаниям придется больше привлекать заемных денег и использовать механизмы проектного финансирования» [9].

Важной представляется и система оценки эффективности проекта. В качестве показателей эффективности проектного финансирования предполагалось использовать чистую приведенную стоимость (NPV); внутреннюю норму рентабельности (IRR); период окупаемости (PBP); дисконтированный период окупаемости (DPBP) и иные показатели, которые на каждом этапе реализации дорожной карты должны быть не ниже минимально установленных значений показателей эффективности в рамках Программы в зависимости от типа и отраслевой принадлежности проекта.

С развитием проектного управления все большее внимание привлекает возможность реализации крупных инфраструктурных проектов с привлечением инвестиций в проекты без наличия залогового имущества. Такой задаче отвечает проектное финансирование (инвестиционный кредит), позволяющий привлечь инвестиции для реализации дорогостоящих достаточно долгосрочных инфраструктурных проектов. Но в условиях санкций банки стараются перестраховаться и редко дают долгосрочные кредиты без надежного залога, и здесь возрастает роль государства, как гаранта возможных рисков. Банки России, кроме ВЭБа, это прежде всего кредитно-депозитные учреждения, они не занимаются инвестициями вне фондового рынка. Необходимо в условиях массовой реализации национальных проектов отобрать пул банков и дать им разрешение на прямую инвестиционную деятельность.

В обеспечении инвестиционными кредитами чрезвычайно велика роль банковского сек- тора. Доля банковского кредитования на протяжении последних лет не превышала $11 \%$. В современных санкционных условиях ЦБ должен расширить свои полномочия, не только заниматься таргетированием инфляции, но и принять на себя ряд функций института развития.

Следовало бы использовать активы банковской системы в виде инвестиционных кредитов. «Их можно увеличить в 3-5 раз вместо 1,5 трлн. руб. получить 4-7 трлн. руб.»*. Необходима также докапитализация институтов развития не только за счет бюджета, но и кредитов Банка России с тем, чтобы предоставлять кредитные ресурсы на уровне сложившегося в 2018 г. процента инфляции.

В заключение отметим, что использование механизма проектного финансирования при реализации национальных проектов требует учета сложившейся практики недовыполнения майских указов Президента. Необходим жесткий контроль выполнения дорожных карт и система ответственности руководителей всех уровней за срыв заданий национальных проектов. Судя по первым результатам, уровень освоения бюджетных средств по исполнению федеральных целевых программ в 2018 г. оказался самым низким за последние годы. «На реализацию ФЦП в 2018 г. было предусмотрено около 500 млрд. руб., уровень кассового исполнения которых осставил 81,5\% (против 90,9\% в 2017 г.). К тому же снизились показатели софинансирования из региональных и местных бюджетов, а также из внебюджетных источников. Аналогичная проблема зафиксирована и при исполнении федеральной адресной инвестиционной программы (ФАИП), на которую выделен более значительный объем средств - свыше 740 млрд. руб. Уровень ее кассового исполнения оценивается в $82 \%$. Настораживают темпы строительства «программных» объектов - по итогам года введено немногим более половины от запланированного (221 из 374)» [10].

Учитывая опыт недофинансирования майских указов, низкий уровень кассового исполнения выделенных бюджетных средств в 2018 г. целесообразна дополнительная мобилизация средств для выполнения чрезвычайно дорогостоящих и исключительно важных для страны национальных проектов. Для этих целей целе-

\footnotetext{
* Опыт развития стран (США и др.) показывает и схему получения таких длинных денег: «путем наращивания дефицита бюджета и выпуска под эту сумму долговременных ценных бумаг, которые покупает Центробанк (имеющий 5 трлн. руб. денежных средств) и другие банки и фонды. Под залог этих ценных бумаг выдаются кредиты под 3-4\% годовых на срок под соответствующие технологические проекты» [11].
} 
сообразно частично использовать фонд наци- проект», все средства которого использовать для онального благосостояния и провести всерос- реализации национальных проектов.

сийский облигационный заем «Национальный

\section{Библиографический список}

1. Проект национального доклада о привлечении частных инвестиций в развитие инфраструктуры и применение механизма ГЧП в РФ. Наццентр ГЧП. М. 2018. С. 5-6.

2. https://www.rbc.ru.economics/19/02/2019/5c6ac3339a79471423e559c7

3. Государственно-частное партнерство. М. ВШЭ. 2010. С. 36-37.

4. Йескомб Э.Р. Государственно-частное партнерство. Основные принципы финансирования. М. Альбина Паблишер. 2015. С. 166.

5. Постановление правительства РФ «Об утверждении программы поддержки инвестиционных проектов, реализуемых на территории РФ на основе проектного финансирования» от 11.10.2014 № 1044 (в ред. от 20.12.2018 № 1758).

6. Там же. Пункт 3 «в».

7. www.consultant.ru/cons/cgi/online.cgi? reg=doc \&base $=$ LAW \&n=315205 \& fld =134\&dst $=1000000001,0 \& r$ $\mathrm{nd}=0.08793013400878413 \# 067821742 \ldots$

8. Саберов Р. Проектное финансирование и его основные преимущества // Экономические науки. 2014. № 12. C. 111.

9. Российская газета. 15.03.2019.

10. Парламентская библиотека. Дайджест прессы. № 52.22 марта 2019. С. 19

11. Аганбегян А.Г. Необходим финансовый форсаж. (Российская газета 12.11.2018). 